DOI: $10.20396 /$ cel.v61i0.8655021

(c) $(1) \Theta$

\title{
MODALIDADE, ETHOS E ESTEREÓTIPOS NOS ACONSELHAMENTOS SOBRE FINANÇAS PARA MULHERES
}

\author{
ANNA FLORA BRUNELLI ${ }^{1}$ \\ RAFAELA DE PAULA VERNI² \\ SANDRA DENISE GASPARINI-BASTOS ${ }^{3}$
}

\begin{abstract}
RESUMO: Neste trabalho, analisamos o ethos de uma obra de autoajuda sobre finanças dirigida especificamente ao público feminino, a fim de revelarmos a imagem que a enunciadora da obra projeta de si pelo seu modo de enunciação. Além disso, analisamos as imagens de mulher que essa enunciadora valoriza e/ou que combate por meio de seus ensinamentos, ou seja, identificamos os estereótipos de mulher que esse discurso colabora para reforçar e/ou transformar. Para operacionalizar a investigação sobre o ethos, analisamos as ocorrências da expressão lexical da modalidade, já que a modalidade é uma das formas de manifestação da subjetividade, mais exatamente uma forma por meio da qual o enunciador expressa sua opinião ou uma atitude em relação ao que diz. Dentre as formas de expressão lexical da modalidade, selecionamos verbos (auxiliares e plenos), adjetivos em posição predicativa e advérbios modais, e nos apoiamos no Funcionalismo como aparato teórico-metodológico específico da Linguística na qualidade de teoria auxiliar. A análise revela que predomina um tom autoritário na obra, ligado à imagem de uma enunciadora assertiva, convicta e focada em suas metas, incluindo a de orientar de forma firme a sua enunciatária. A análise revela, ainda, que a obra reforça o estereótipo tradicional de gênero feminino, segundo o qual as mulheres são menos propensas às finanças do que os homens.
\end{abstract}

Palavras-chave: discurso de autoajuda; mulheres; modalidade; ethos; estereótipos.

ABTRACT: In this work, we analyze the ethos of a self-help book on finances directed specifically to the female audience, in order to reveal the image that the enunciator of the book projects of herself by its mode of enunciation. In addition, we analyze the images of women that this enunciator values and/or combat through their teachings, that is, we identify the stereotypes of women that this discourse collaborates to reinforce and/or transform. In order to operationalize the ethos research, we analyze the occurrences of the lexical expression of the modality, since modality is one of the forms of manifestation of subjectivity, more precisely a form through which the enunciator expresses his opinion or an attitude towards what says. Among the forms of lexical expression of the modality, we selected verbs (auxiliary and full), adjectives in predicative position and modal adverbs, and we rely on Functionalism as a specific theoretical-methodological apparatus of Linguistics as an auxiliary theory. The analysis reveals that an authoritarian tone prevails in the book, linked to the image of an assertive, convinced and focused enunciator in its goals, including guiding the reader in an assertive way. The

${ }^{1}$ Universidade Estadual Paulista (UNESP), Câmpus de São José do Rio Preto, São José do Rio Preto, SP, Brasil. anna.brunelli@unesp.br

${ }_{2}$ Mestre em Linguística pelo Programa de Pós-Graduação em Estudos Linguísticos da Universidade Estadual Paulista (UNESP), Câmpus de São José do Rio Preto, São José do Rio Preto, SP, Brasil.rpverni@gmail.com

${ }^{3}$ Universidade Estadual Paulista (UNESP), Câmpus de São José do Rio Preto, São José do Rio Preto, SP, Brasil. sandra.gasparini@unesp.br 
analysis further reveals that the book reinforces the traditional gender stereotype according to which women are less prone to finances than men.

Keywords: self-help discourse; women; modality; ethos; stereotypes.

\section{INTRODUÇÃO}

Na luta das mulheres para conquistar direitos iguais aos dos homens no âmbito político, jurídico, trabalhista e civil, as diversas transformações econômicas, sociais e culturais que ocorreram no mundo ao longo das últimas décadas afetaram significativamente a condição feminina. Conforme Alves (2016), o empoderamento das mulheres e a redução das desigualdades de gênero vêm representando um ponto essencial da etapa atual da história da humanidade. Respaldado no relatório El Progreso de las Mujeres en el Mundo 2015-2016, desenvolvido pela ONU Mujeres, em 2015, o autor observa que a emancipação feminina tem percorrido um caminho que passa pela conquista de direitos essenciais da mulher, incluindo a conquista da igualdade de oportunidades na família e na sociedade. Para o autor, o "empoderamento das mulheres - de todas as gerações - é um anseio cada vez maior das organizações da sociedade civil e um processo que avança nas diversas instâncias de poder dos Estados nacionais" (ALVES, 2016, p. 630).

No entanto, embora seja evidente que a mulher desfruta de mais liberdade profissional, financeira e sexual, ainda há diferenças significativas entre os cargos ocupados no mercado de trabalho por homens e mulheres, assim como desigualdade entre os salários, mesmo quando as funções são equivalentes. Embora se reconheça, na atualidade, que o progresso das sociedades não pode conviver com a discriminação e a segregação de gênero, nem todo processo de desenvolvimento impulsiona a igualdade entre homens e mulheres. Assim, apesar do aumento evidente da participação feminina no mercado de trabalho e da diversificação de espaços ocupados pelas mulheres, ainda se mantém a divisão sexual entre trabalho produtivo e reprodutivo, o que limita a autonomia e o empoderamento das mulheres na família e na sociedade.

A esse respeito, Biroli (2018) trata de resquícios da ideologia do patriarcado ainda existentes no modo de produção capitalista atual. Alguns dados apresentados pela autora retratam esse cenário de desigualdades. Vejamos: nas últimas décadas do século XX, o percentual de mulheres economicamente ativas passou de $18,5 \%$ para cerca de $55 \%$, tendo alcançado um teto de $59 \%$ em 2005 . Apesar disso e apesar de a desigualdade salarial entre homens e mulheres ter sido reduzida ao longo dos anos, a diferença entre o rendimento médio das mulheres e o dos homens ainda permanece em torno de $25 \%$, e a profissionalização das mulheres não garantiu acesso igualitário a todos os tipos de ocupações. Segundo Biroli (2018),

na conformação conjunta do capitalismo e do patriarcado em seus padrões atuais, as mulheres são posicionadas como um grupo onerado pelo cotidiano de trabalho prestado gratuitamente, direcionado a ocupações específicas, menos remunerado que o dos homens que desempenham as mesmas atividades e sub-representadas na política (BIROLI, 2018, p. 23). 
Nesse contexto, estereótipos e preconceitos ajudam a encurralar as mulheres em nichos específicos de trabalho, ou seja, serviços nas áreas ditas femininas normalmente nas áreas do ensino ou da saúde, reforçando a segregação dentro do mercado de trabalho. Quanto a isso, Bruschini (1994) observa que, aparentemente, as mulheres

vão fazendo novas escolhas, procurando vencer barreiras e superar preconceitos. No entanto,
ainda são influenciadas por dois mecanismos convergentes: de um lado, processos socializadores
que se reproduzem através da família, da escola e dos meios de comunicação, que tendem
a orientá-las na direção de ocupações que são consideradas mais próprias para as mulheres;
de outro, uma certa sabedoria da conciliação, que faz com que as mulheres, cientes de que
forçosamente terão a seu cargo responsabilidades familiares além das profissionais, escolham
ocupações que acreditam ser compatíveis com esta situação (BRUSCHINI, 1994, p. 191-192).

Enfim, fica claro que, apesar do aumento evidente da participação das mulheres no mercado de trabalho e da diversificação de espaços ocupados por elas ao longo dos anos, elas ainda enfrentam muitos obstáculos nesse meio, dentre eles: a discriminação de gênero, a desigualdade salarial comparada aos homens que exercem os mesmos cargos, a falta de reconhecimento e a lenta progressão de suas carreiras, o acúmulo de tarefas, uma vez que as responsabilidades no lar ainda não foram divididas, especialmente para o caso das mulheres que decidem ter filhos.

Dentro desse contexto, emergem vários discursos que se destinam a refletir sobre a questão, a partir das mais diferentes perspectivas. O objetivo mais amplo deste trabalho, que se ancora na Análise do Discurso de linha francesa, é analisar o ethos de um desses discursos, o discurso de autoajuda destinado especificamente a mulheres, com obras que tematizam finanças, negócios e/ou mercado profissional. De um modo geral, essas obras destinam-se a auxiliar as mulheres a superar os desafios impostos pela sociedade capitalista para serem bem-sucedidas, de modo que se sintam confiantes e independentes para enfrentar as desigualdades que ainda dominam o mundo dos negócios, que é, como se sabe, um nicho considerado particularmente masculino.

Dentre as diversas obras de autoajuda para mulheres com essa temática que estão sendo comercializadas atualmente, podemos citar títulos como Mulheres ousadas chegam mais longe (FRANKEL, 2005), As mulheres e o dinheiro (ORMAN, 2007) e Ganhar, gastar, investir: o livro do dinheiro para mulheres (DAMIANI; ALMEIDA, 2016). Todas essas obras pretendem, de alguma forma, oferecer aconselhamentos para ajudar as mulheres a superarem os obstáculos do mercado financeiro e a obterem sucesso profissional.

Para o desenvolvimento deste trabalho, selecionamos a obra Mulheres boazinhas não enriquecem, de Louise P. Frankel (2006), que tomamos como representativa do gênero. Nessa obra, a autora se apresenta como presidente da Corporate Coaching International, empresa da Califórnia especializada em desenvolvimento de liderança e formação de equipes de executivos. Nessa condição, a autora se coloca como detentora de conhecimento financeiro e como uma palestrante capaz de oferecer orientações práticas para a construção de uma carreira de sucesso. Baseando-se em fatos e em experiências de sua 
própria vivência como mulher empreendedora, oferece conselhos e normas de comportamento para que a mulher seja bem-sucedida financeiramente, agindo de maneira independente. $\mathrm{O}$ foco do livro não é apenas ensinar as mulheres a desenvolver um bom planejamento financeiro, mas também convencê-las de que podem enriquecer, desde que mudem seu modo de se relacionar com o dinheiro.

Considerando que o ethos diz respeito à imagem que o enunciador do discurso projeta de si por meio de seu modo de enunciar, neste trabalho pretendemos identificar, a partir da análise do ethos da obra selecionada, a imagem dessa enunciadora bem-sucedida no mundo dos negócios que se propõe a ensinar outras mulheres a lidar com finanças. Além disso, pretendemos analisar também a(s) imagem(ns) de mulher(es) que valoriza e/ou que a obra combate por meio de seus ensinamentos, ou seja, pretendemos identificar as imagens e os estereótipos de mulher que esse discurso colabora para reforçar e/ou transformar, com o intuito de darmos algum tipo de contribuição para as reflexões desenvolvidas atualmente no âmbito das ciências humanas sobre a emancipação feminina.

\section{ETHOS, ÍNDICES TEXTUAIS E MODALIDADE}

Para analisarmos a imagem da enunciadora do discurso de autoajuda sobre finanças dirigido a mulheres, empregamos o aparato teórico-metodológico da Análise do Discurso de linha francesa. Desse quadro, destacamos as reflexões de Maingueneau $(2005,2008,2010)$ sobre a noção de ethos discursivo. ${ }^{4}$

Seguindo a proposta do autor, a análise do ethos pode se basear em índices textuais de diversas ordens; é por meio desses índices, que vão desde a escolha do registro até o planejamento textual, que o leitor/ouvinte tem condições de formar uma representação do enunciador do discurso.

Para traçar a imagem da enunciadora do discurso de autoajuda para mulheres sobre finanças, optamos por analisar ocorrências, na obra selecionada, da expressão lexical da modalidade. Julgamos tal escolha coerente para o desenvolvimento da análise, já que a modalidade é uma das formas de manifestação da subjetividade, mais exatamente uma forma por meio da qual o enunciador expressa sua opinião ou atitude em relação ao que diz. Dentre as formas de expressão lexical da modalidade, selecionamos verbos (auxiliares e plenos), adjetivos em posição predicativa e advérbios modais, e nos apoiamos no Funcionalismo como aparato teórico-metodológico específico da Linguística na qualidade de teoria auxiliar.

Essa opção nos aproxima de outros trabalhos que também consideraram a análise da modalidade como uma via produtiva para o desenvolvimento de uma reflexão sobre o ethos do discurso de autoajuda e seus subtipos (ligados a temáticas e/ou a públicos específicos), tal como Brunelli (2004), que analisa o discurso de autoajuda sobre sucesso para adultos, Furlan (2013), que analisa o discurso de autoajuda para adolescentes, e Ueda (2014), que analisa o discurso

${ }^{4}$ Maingueneau $(2005,2008,2010)$ adapta a noção de ethos retórico para o quadro teóricometodológico da Análise do Discurso de linha francesa. Dada a limitação de espaço, optamos por dispensar uma apresentação detalhada da noção. 
de autoajuda para a terceira idade. A opção pela perspectiva funcionalista é uma forma de garantir um tratamento não redutor, tendo em vista que estudos dessa natureza descrevem a função dos modalizadores nos níveis pragmático, semântico e sintático de forma integrada.

Dentre as várias propostas de classificação das modalidades, adotamos a classificação proposta por Hengeveld (2004), porque essa proposta não apenas identifica o domínio semântico a partir do qual a avaliação é feita, como também considera o alvo dessa avaliação, ou seja, a parte do enunciado que é modalizada, o que nos permite identificar variações nos efeitos de sentido desencadeados pelos modalizadores.

Segundo o critério do domínio semântico, Hengeveld (2004) classifica a modalidade em cinco tipos: modalidade facultativa, modalidade deôntica, modalidade volitiva, modalidade epistêmica e modalidade evidencial.

A modalidade facultativa refere-se às capacidades intrínsecas ou adquiridas. A modalidade deôntica associa-se ao que é legal, moral e socialmente permitido; em outras palavras, é o que está relacionado ao que é permissível ou proibido, obrigatório ou necessário. A modalidade volitiva está relacionada ao que é desejável. A modalidade epistêmica está relacionada ao que se sabe em relação ao mundo real. Por fim, a modalidade evidencial se relaciona com a fonte da informação contida em uma sentença. Trabalhos posteriores (HENGEVELD, 2011; HENGEVELD; HATTNHER, 2015) excluem a evidencialidade da categoria das modalidades, tratando-a como uma categoria separada. Da mesma forma, optamos por considerar apenas quatro dos cinco tipos modais anteriormente propostos.

Considerando o segundo critério, isto é, o alvo de avaliação, Hengeveld (2004) propõe que a modalidade seja orientada para três tipos de alvos diferentes: para o participante, para o evento referido na proposição e para a própria proposição.

A partir da combinação dos dois parâmetros propostos, o autor verifica quais são as possibilidades de modalização, excluindo aquelas cujo domínio semântico, de acordo com a lógica, não tem possibilidade de atuar no alvo de avaliação. Desse modo, o autor reconhece a modalidade facultativa orientada para o participante e para o evento, a modalidade deôntica orientada para o participante e para o evento, a modalidade volitiva orientada para o participante, para o evento e para a proposição ${ }^{5}$ a modalidade epistêmica orientada para o evento e para a proposição.

A análise do ethos está baseada no levantamento das ocorrências de manifestação de modalidade encontradas nas 100 primeiras páginas da obra em análise. Estamos nos baseando no método de amostragem, uma vez verificado que os resultados semânticos que encontramos nessas páginas tendem a se manter até o final, sendo uma representação significativa do todo.

Para a análise da modalidade, primeiramente fizemos um levantamento das ocorrências modais de verbos (auxiliares e plenos), adjetivos em posição predicativa e advérbios, e suas respectivas locuções, classificando-as de acordo

${ }^{5}$ Embora seja um domínio lógico possível, Olbertz e Gasparini-Bastos (2013) questionam a existência, nas línguas naturais, de uma modalidade volitiva orientada para a proposição. 
com o domínio semântico (subtipo modal) e com a orientação da modalidade, conforme proposta adotada.

Na sequência, apresentamos os resultados desse levantamento e os exemplos representativos de cada subtipo modal analisado. A partir desses resultados, tratamos de analisar o ethos do discurso, procurando identificar o(s) tom(ns) ${ }^{6}$ do discurso e a(s) imagem(ns) da enunciadora que projeta.

\section{ANÁLISE DO ETHOS: MODALIDADE E TONS}

Feito o levantamento e a devida classificação dos itens lexicais modais encontrados nas primeiras 100 páginas da obra de Frankel (2006), obtivemos os seguintes resultados, apresentados na tabela a seguir:

\begin{tabular}{|c|c|c|}
\hline Modalidade & Alvo da avaliação & Número de ocorrências \\
\hline \multirow{4}{*}{ Volitiva } & Participante & 33 \\
\hline & Evento & - \\
\hline & Proposição & - \\
\hline & Subtotal: & $33(13.8 \%)$ \\
\hline \multirow{4}{*}{ Facultativa } & Participante & 37 \\
\hline & Evento & 19 \\
\hline & Proposição & - \\
\hline & Subtotal: & $56(23.3 \%)$ \\
\hline \multirow{4}{*}{ Deôntica } & Participante & 42 \\
\hline & Evento & 17 \\
\hline & Proposição & - \\
\hline & Subtotal: & $59(24.6 \%)$ \\
\hline \multirow{4}{*}{ Epistêmica } & Participante & - \\
\hline & Evento & 41 \\
\hline & Proposição & 51 \\
\hline & Subtotal: & $92(38.3 \%)$ \\
\hline \multirow{4}{*}{ Total geral } & Participante & $112(32 \%)$ \\
\hline & Evento & $77(46.7 \%)$ \\
\hline & Proposição & $51(21.3 \%)$ \\
\hline & & $240(100 \%)$ \\
\hline
\end{tabular}

Tabela 1. Ocorrências de modalizadores em Frankel (2006).

${ }^{6}$ Para Maingueneau (2005), há três elementos que constituem o campo do ethos. O primeiro deles é a voz específica que habita a enunciação do texto. A essa vocalidade, entendida como um ideal de entonação, Maingueneau prefere chamar de tom, para que possa valer tanto para o oral quanto para o escrito. O tom está ligado a um caráter e a uma corporalidade, que são os outros dois elementos que recobrem o ethos discursivo. O caráter corresponde a um conjunto de traços "psicológicos" que o leitor/ouvinte atribui espontaneamente à figura do enunciador em função de seu modo de dizer. Já a corporalidade diz respeito a uma certa aparência corporal relacionada a um modo de se movimentar no espaço social, o que pode incluir até mesmo um modo de se vestir. 
Como observamos na tabela, os modais epistêmicos foram os mais frequentes, seguidos dos deônticos e dos facultativos, que ocorreram em números praticamente iguais, e dos volitivos, menos recorrentes na obra. Na sequência, analisamos de que maneira cada tipo modal contribui para a constituição do ethos.

\subsection{Modalidade epistêmica}

Conforme aponta Gasparini-Bastos (2004), a modalidade epistêmica está relacionada ao conhecimento ou crença que cada enunciador tem (ou diz ter) a respeito dos estados de coisas relacionados em seu discurso. A atitude do falante diante de um enunciado epistemicamente modalizado pode variar em graus de certeza e de dúvida ou possibilidade. Segundo Neves (1996, p. 178), a avaliação epistêmica "se situa em algum ponto do continuum que, a partir de um limite preciso, onde está o (absolutamente) certo, se estende pelos limites e indefinidos graus do possível". Considerando a divisão entre o certo e o possível, prevista para a modalidade epistêmica, passamos a analisar os modalizadores epistêmicos presentes na obra.

Muitas das ocorrências desse tipo de modalidade estão representadas pela construção formada por verbo auxiliar poder + verbo no infinitivo, um caso de modalidade epistêmica voltada para o evento e associada à expressão da dúvida, por meio da qual a enunciadora apresenta um evento como possível, sem assumir a responsabilidade por esse julgamento. A ocorrência desse tipo modal é bastante frequente junto a enunciados hipotéticos, enunciados que se prestam a contar uma história fictícia ou a descrever algo que pode vir a acontecer, normalmente uma circunstância negativa. Vejamos o excerto abaixo:

(1) Ir viver com alguém pode parecer uma ideia maravilhosa quando vocês estão loucos um pelo outro. (...) Vocês têm de conversar sobre 1) quem é dono do quê, 2) quem vai pagar as dívidas feitas pelos dois e 3) como é que vocês vão dividir as despesas da casa. Pode parecer pouco romântico agir dessa maneira, mas você pode acabar perdendo uma quantidade considerável de seus bens se não fizer isso. (FRANKEL, 2006, p. 92; grifos nossos)

Diante de casos como (1), verificamos que os contextos em que aparecem os marcadores de dúvida são os contextos que preveem consequências negativas que podem vir a acontecer. Ou seja, a modalidade epistêmica aparece, muitas vezes, associada a contextos hipotéticos que projetam uma situação ruim, caso a enunciatária não observe os alertas e as orientações que lhes estão sendo passados.

Já no caso da modalidade epistêmica orientada para a proposição, verificamos, na obra analisada, que os elementos epistêmicos que predominam são os indicativos de certeza por parte da enunciadora, como mostra o excerto (2):

(2) Se você não está vivendo conscientemente em outras áreas, com certeza não deve ter consciência de sua maneira de gastar e investir dinheiro. (FRANKEL, p. 71, 2006; grifos nossos) 
Em (2), a locução adverbial com certeza certifica a opinião convicta da enunciadora. Dados assim nos indicam que a enunciadora dessa obra procura não deixar margem para dúvida em relação ao conteúdo que enuncia, expressando confiança e segurança em seu discurso.

O tom de conviç̧ão pode ser marcado, também, pela ausência de marcas modais. No excerto (3), por exemplo, não há emprego de modalizadores, o que gera o efeito de sentido de absoluta convicção do enunciador sobre o que diz:

(3) Um dos principais motivos pelos quais as mulheres não investem tanto quanto os homens é o fato de não terem conhecimentos necessários para se sentir seguras nesse setor. A única maneira de superar esse medo é instruir-se. Saber é poder - principalmente quando se trata de dinheiro. (FRANKEL, 2006, p. 183)

Assim, podemos dizer que a enunciadora projeta de si a imagem de uma mulher experiente também por meio de enunciados afirmativos. Essa enunciadora, revelando certeza absoluta ao enunciar, ocupa uma posição de saber e demonstra seu conhecimento sobre os temas de que trata.

Identificamos, ainda, na obra em análise, manifestações de verbos que expressam dúvida, como achar e acreditar, que tomam por alvo toda a proposição, mostrando uma enunciadora que, num primeiro momento, parece titubear sobre a verdade de seu enunciado. Vejamos:

(4) Se você não é tão rica quanto quer ser, acho que (sejam quais forem os motivos) não se concentrou nisso nem visualizou a riqueza como parte de sua vida. (FRANKEL, p. 34, 2006; grifos nossos)

(5) Ser analfabeta financeiramente é uma escolha, assim como decidir enriquecer. Em minha placa de carro personalizada está escrito CHOISEZ, pois acredito que tudo é uma questão de escolha (FRANKEL, 2006, p. 73; grifos nossos)

No entanto, defendemos que não se trata exatamente de uma autêntica manifestação de dúvida. Parece-nos mais uma estratégia discursiva destinada a aproximar a enunciadora de sua enunciatária, ao atenuar a possível imagem de prepotência que poderia emergir do fato de a enunciadora ser sempre convicta do que diz. Logicamente, o tom do discurso seria bem mais convicto e direto (e até mais autoritário) se ela afirmasse "Se você não é tão rica quanto quer ser, não se concentrou nisso o suficiente" - ou seja, nesse caso, a enunciadora estaria explicitamente culpando a enunciatária pela sua condição financeira negativa. A manifestação de dúvida parece servir, nesses termos, para amenizar um possível efeito negativo associado ao modo de enunciar convicto da enunciadora.

\subsection{Modalidade deôntica}

A modalidade deôntica foi a segunda mais recorrente na obra, o que imprime um tom autoritário ao discurso. Nos excertos (6) e (7), as expressões deônticas não 
deve e tem de constituem ordens que recaem diretamente sobre o participante, que, no caso, corresponde à enunciatária do discurso:

(6) Você não deve permitir o acúmulo de dinheiro de nenhum débito. (FRANKEL, 2006, p. 20; grifos nossos)

(7) Enriquecer exige que você esteja no leme do seu barco (...). Para isso, você tem de ser esperta no tocante a dinheiro, interessada na forma pela qual seu dinheiro é gasto e investido e ter uma vida financeira. (FRANKEL, 2006, p. 67; grifos nossos)

Nesse mesmo campo semântico, encontramos outras formas de expressão que reforçam o tom de autoridade do discurso, como é o caso da locução ter a obrigação de, presente no excerto (8):

(8) Se emoções destrutivas estão governando a sua vida, você tem a obrigação de investir na criação de um futuro emocional e financeiro mais saudável. (FRANKEL, 2006, p. 110; grifos nossos)

Já as ocorrências de modais deônticos voltados para o evento se apresentam como ordens que não são assumidas explicitamente pela enunciadora; mesmo assim, o tom instrutivo e autoritário do discurso não fica atenuado. Vejamos outro exemplo:

(9) Seja o que for que tenham ouvido dos pais, entraram num mundo onde foram levadas a sentir que os homens sabem mais quando se trata de dinheiro, que as mulheres são responsáveis pelo lar e que quando é preciso fazer uma escolha entre cuidar de si mesmas e cuidar dos outros - bom, não existe realmente uma escolha. (FRANKEL, p. 67, 2006; grifos nossos)

No excerto acima, a instrução "é preciso fazer uma escolha" não recai sobre um participante específico, como, por exemplo, a enunciatária, mas funciona como uma orientação de cunho geral, a ser seguida por todos. Ainda que atenuado, o tom de autoridade prevalece no discurso.

\subsection{Modalidade facultativa}

O terceiro tipo de modalidade mais recorrente na obra é a facultativa. Uma vez que essa modalidade expressa capacidade, condições de se fazer algo, ela está intrinsecamente ligada à expressão de otimismo, tom típico do discurso de autoajuda convencional, como podemos notar no excerto (10), por meio de emprego do verbo auxiliar poder: ${ }^{7}$

\footnotetext{
${ }^{7}$ Para análises mais detalhadas sobre o verbo poder com valor modal facultativo, ver Brunelli e Gasparini-Bastos $(2008,2011)$.
} 
(10) Nada disso significa que você não pode enriquecer como professora, assistente social ou enfermeira, porque pode. (FRANKEL, 2006, p. 206; grifos nossos)

Há, portanto, certo otimismo na obra em análise, o que é mesmo esperado, já que se trata de uma obra de autoajuda. No entanto, se compararmos essas ocorrências ao número de deônticos somados ao alto índice de imperativos, verificamos que o tom otimista do discurso de autoajuda é um dos menos fortes na obra em análise, diferente do discurso de autoajuda dirigido a público adulto em geral, conforme os resultados obtidos por Brunelli (2004).

Destacamos, ainda, a ocorrência de modais facultativos dirigidos à enunciatária e empregados no modo negativo, ocorrências que revelam as supostas dificuldades/incapacidades das mulheres, como podemos notar em (11):

(11) E não só os carros e a casa que a gente negligencia. Não conseguimos tempo para tirar aquele vestido caríssimo do armário para a costureira fazer uns ajustes e não fazemos manutenção de nossos equipamentos de ginástica (bicicletas ergométricas, esteiras, etc.). Tudo porque colocamos nossas prioridades pessoais no fim da lista de tarefas. (FRANKEL, 2006, p. 96; grifos nossos)

\subsection{Modalidade volitiva}

Com relação à modalidade volitiva, ainda que pouco frequentes, suas ocorrências não deixam de projetar a imagem de uma enunciadora esperançosa de que seus aconselhamentos tragam benefícios para a enunciatária. Notamos, então, um tom de esperança nas expectativas positivas da enunciadora com relação ao que pretende ensinar à enunciatária, como podemos ver no seguinte excerto:

(12) Espero que, nestas páginas, vocês encontrem a coragem e a sabedoria necessárias para tomar todas as providências indispensáveis para desfrutar a riqueza da vida. (FRANKEL, p. 5, 2006; grifos nossos)

No entanto, alguns volitivos identificados na obra podem ser reinterpretados como deônticos, conforme verificamos no excerto (13):

(13) Embora você queira ouvir as pessoas que podem ajudá-la a evitar os perigos ocultos em seu caminho para a riqueza, não vai querer que elas determinem a direção que você vai tomar (FRANKEL, p. 55, 2006; grifos nossos).

Notamos que o tom autoritário do discurso se manifesta por outras vias, como no caso acima, mediante o emprego da expressão não vai querer. Nesse excerto, observamos a associação de dois volitivos (querer e não querer), porém o segundo pode ser reinterpretado como um deôntico, cujo sentido pode ser esclarecido pelas seguintes paráfrases: "Você não deve querer/deixar que as pessoas determinem a 
direção que você vai tomar" ou "Não deixe que as pessoas determinem a direção que você vai tomar".

Casimiro (2007), ao estudar volitivos com valor deôntico adotando a abordagem funcionalista, parte da hipótese de que, em relações em que o enunciador ocupa uma posição hierárquica mais alta que seu enunciatário, expressões de desejo podem ser interpretadas deonticamente - como ele comprova ao analisar discursos presidenciais.

Podemos também partir dessa hipótese, uma vez que a cena enunciativa típica de autoajuda é aquela na qual o enunciador, assumindo um lugar de saber, se coloca numa posição hierarquicamente superior ao enunciatário, ditando-lhe autoritariamente seus comportamentos. Desse modo, no contexto do exemplo (13), o modal volitivo indica que a mulher poderia atender seus desejos, mas acaba por receber uma ordem ("não queira que determinem a direção que você vai tomar"). Assim sendo, o desejo na verdade é uma ordem, o que contribui novamente para identificarmos o tom autoritário presente no discurso. Vejamos outro excerto semelhante:

(14) Agora pegue sua agenda e reserve uma hora por mês como o tempo que vai usar para começar a ficar rica. Estou querendo dizer agora. Você pode usar esse tempo para ler uma revista sobre investimentos, fazer pesquisa na internet ou conversar com seu marido ou um parente sobre questões financeiras. (FRANKEL, 2006, p. 70; grifos nossos)

No excerto (14), o emprego do verbo querer ("estou querendo dizer agora") poderia, a princípio, representar uma manifestação da modalidade volitiva. Mas, na verdade, é uma expressão típica de um enunciador com autoridade sobre alguém subalterno: uma mãe e um filho, uma professora e um aluno, o que nos permite reinterpretar o contexto como tendo um valor deôntico. Some-se a isso a presença dos imperativos pegue e reserve, que também revelam um tom de autoridade.

De fato, notamos na obra uma alta incidência de verbos no imperativo, projetando uma imagem de enunciadora autoritária, que instaura regras, ordens e deveres que devem ser cumpridos pela sua enunciatária, reforçando, assim, o tom de autoridade.

Ainda com relação ao excerto (14), o verbo auxiliar pode poderia gerar, a princípio, ambiguidade de classificação: poderíamos interpretá-lo como um epistêmico "Você tem a possibilidade de usar esse tempo para ler uma revista" ou como facultativo "Você consegue usar esse tempo para ler uma revista". No entanto, diante do contexto deôntico, é muito mais coerente classificá-lo como um modal deôntico, reinterpretando a sugestão como uma permissão disfarçada ("Você tem permissão para usar seu tempo para aprender sobre finanças"). Como já apontava Neves (2006), o recurso ao contexto é fundamental para o estabelecimento do significado dos valores modais.

Além dos tons observados na análise dos elementos modais, verificamos casos em que a enunciadora parece tentar atenuar o caráter prescritivo de seus enunciados, o que pode ser verificado em excertos como (15): 
(15) Personalize as palavras deste livro. É o que faz dele um livro diferente dos outros que tratam de planejamento financeiro. Não é apenas uma lista de coisas pra fazer; também é sobre o que você pensa e sente. (FRANKEL, 2006, p. 38)

Nesse excerto, que pode ser considerado uma ocorrência de ethos dito, já que se trata de um enunciado em que o discurso tematiza a si mesmo, notamos que a obra é apresentada como se fosse uma obra que não se destina apenas a passar instruções, mas também a lidar com os sentimentos e pensamentos das mulheres, o que pode ser tomado como uma tentativa de atenuar seu caráter prescritivo.

Assim, além dos temas sobre reeducação financeira, a obra trata dos possíveis confrontos internos pelos quais uma mulher pode passar, como medo, desconforto, dúvidas e desamparo em situações específicas, tais como divórcio ou possível morte do cônjuge; conforme observamos, todas essas situações hipotéticas estão, de um modo ou de outro, relacionadas com a possibilidade de a mulher perder dinheiro. Para tratar dessas situações, a enunciadora assume um tom diferente, enunciando como se fosse uma pessoa próxima da enunciatária, uma amiga. A esse respeito, vejamos os seguintes excertos:

(16) Minha amiga, você tem de superar essa barreira se quiser ficar rica. (FRANKEL, 2006, p. 35; grifos nossos)

(17) Diga não. Sim, eu sei que é difícil. Sim, entendo que vai contra tudo em que você acredita. Sim, eu compreendo que você nunca vai ser independente financeiramente se continuar rasgando dinheiro. Depois das primeiras vezes, dizer não fica mais fácil - portanto, comece a praticar agora. (FRANKEL, 2006, p. 249)

(18) Sofro de uma forma rara de gastos motivada por pressão social que também pode afligir algumas de vocês. (FRANKEL, 2006, p. 127)

Podemos verificar que, no excerto (16), a enunciadora se dirige diretamente à enunciatária por meio do vocativo minha amiga. Já em (17), ela se apresenta como alguém que conhece o pensamento e os sentimentos da enunciatária, o que lhe permite aconselhá-la. Do mesmo modo, em (18), a enunciadora se aproxima da enunciatária ao afirmar que padece do mesmo mal que pode acometer sua enunciatária, o que deve, certamente, favorecer algum tipo de identificação entre elas. Dessa maneira, a enunciadora procura aproximar-se da enunciatária, abrindo um espaço de troca de confidências, como se fossem verdadeiramente amigas. Assim, além de criar uma atmosfera de bate-papo, com esses recursos, o discurso dessa obra também assume um tom mais amistoso, que pode ser até entusiasta e encorajador, como podemos notar em (19):

(19) Se você leu até aqui, então já investiu tempo e dinheiro em sua prosperidade econômica. Meus parabéns! Agora pegue sua agenda e reserve uma hora por 
mês como tempo que vai usar para começar a ficar rica. (FRANKEL, 2006, p. 70; grifos nossos)

Esse tom amigável e entusiasta diz respeito ao ethos de uma amiga verdadeira, conselheira e compreensiva, alguém com quem se pode contar.

Por fim, identificamos na obra excertos em que o discurso de autoajuda para mulheres valoriza a ação e o fazer, nos mesmos termos que o discurso de autoajuda convencional:

(20) Transforme suas preocupações com dinheiro num foco de geração de riqueza. Depois é só pôr em prática as dicas apresentadas neste livro. (FRANKEL, 2006, p. 34)

(21) O universo recompensa a ação. Você vai descobrir isso quando se comprometer com a sua independência financeira. (FRANKEL, 2006, p. 39)

Ao assumir um tom objetivo e otimista e ao promover uma mulher objetiva, independente, determinada e focada, que valoriza as ações e está comprometida com a construção do próprio sucesso, podemos dizer que o discurso de autoajuda sobre finanças para mulheres aproxima-se um pouco do discurso de autoajuda convencional. Por outro lado, conforme já identificamos, predomina no discurso de autoajuda para mulheres sobre finanças o tom autoritário, o que o diferencia, então, do discurso de autoajuda convencional para adultos em geral, que é bem mais otimista.

\section{IMAGENS E ESTEREÓTIPOS DE MULHER}

Conforme análise desenvolvida na seção anterior, o tom autoritário da enunciadora é bastante evidente não só pelo emprego de modais deônticos específicos, mas também por outras vias, tais como a associação entre deônticos e imperativo e o emprego de volitivos com valor de autoridade. A enunciadora, experiente e segura, assume como objetivo educar suas leitoras para "derrubarem" barreiras, confrontarem a voz da sociedade, que, segundo afirma, não só as subestima, como também lhes dita valores tradicionais e mensagens dúbias que inibem sua capacidade de adquirir riqueza. Nesse sentido, surgem questões relacionadas a certos paradigmas sociais que têm de ser quebrados, como a educação tradicional de mulheres, a suposta falta de iniciativa das mulheres para negócios, a suposta permanência das mulheres na sua zona de conforto, tal como se nota nos excertos abaixo:

(22) "Mulheres boazinhas" não enriquecem em grande parte por causa das mensagens sociais que recebem quando estão crescendo:

- Dinheiro é poder, e a maioria das meninas não é ensinada a ser poderosa - a maioria é ensinada a ser 'boa'. 
- As meninas são educadas para cuidar dos outros, para ser acolhedoras e acomodar as coisas na vida em sociedade - e não necessariamente para ser arrimo da família (...) (FRANKEL, 2006, p. 21)

(23) (...) ensinaram-nos implícita ou explicitamente que é igualmente importante sermos boas, acolhedoras e cooperativas; que nosso verdadeiro papel gira menos em torno do dinheiro que das relações afetivas (FRANKEL, 2006, p. 20)

Conforme podemos notar, na obra em análise, combate-se a imagem da "mulher boazinha", aquela cujo papel gira em torno das relações afetivas e que é presa aos padrões antigos; essa mulher, que é boa, acolhedora e cooperativa, não pensa em si própria e se sente pouco à vontade para falar de dinheiro. Por outro lado, valoriza-se a imagem da "mulher adulta": trata-se de uma mulher que não se deixa levar pelas próprias emoções; é inteligente, reflexiva, assertiva, focada e capaz de adquirir riqueza sem medo de arriscar e de investir. Considerando-se essa imagem da mulher boazinha, o tom autoritário, objetivo e assertivo da enunciadora do discurso de autoajuda pode ser considerado como uma espécie de contraponto à atitude passiva que parece caracterizar essa imagem de "mulher boazinha".

Vejamos outros excertos em que se notam as diferenças entre a imagem da "mulher boazinha" e da "mulher adulta":

(24) "Mulheres boazinhas" não enriquecem porque se concentram mais nas necessidades dos outros que nas próprias e evitam dar os passos indispensáveis para se tornarem realmente independentes. Você não vai ficar rica sendo "boa menina", mas pode ficar rica tornando-se uma mulher adulta - e não deixando ninguém impedi-la de chegar lá. (FRANKEL, 2006, p. 39)

(25) Eis aqui sua primeira oportunidade de mostrar a si mesma que não é apenas uma "mulher boazinha" e sim uma mulher inteligente. (FRANKEL, 2006, p. 277)

(26) "Mulheres boazinhas" são aliadas daqueles que preferem mantê-las na ignorância - sobre dinheiro ou sobre qualquer outra coisa, diga-se de passagem. Mulheres adultas não dão seu consentimento. (FRANKEL, 2006, p. 82)

Como podemos notar, a enunciadora considera que a enunciatária, a quem identifica como "mulher boazinha", não tem as qualidades necessárias para atingir seus objetivos na área de finanças. Para que ela possa obter êxito nesse propósito, seu comportamento tem de ser justamente o oposto: ela precisa ser uma mulher adulta e inteligente. Logo, parte do pressuposto de que não é nem adulta, nem inteligente, mas sim incapaz de lidar com os percalços do mundo dos negócios porque é "boazinha" demais, o que certamente não é nada benéfico às mulheres, já que lhes projeta uma imagem de pouca competência. 
Um breve levantamento do léxico que gravita em torno de cada uma das duas imagens de mulheres identificadas acima nos permite verificar claramente as diferenças entre as imagens: de um lado, a mulher boa, acolhedora, cooperativa; de outro, a mulher rica, assertiva, esperta, poderosa, adulta, inteligente.

No discurso em análise, a condição de mulher boazinha e emotiva é considerada tão negativa que é até assemelhada a uma doença, a "síndrome da mulher boazinha", expressão muito recorrente em toda a obra:

(27) As mulheres querem que as pessoas que amam tenham o que elas têm e vão sacrificar seu bem-estar para atender às necessidades dos outros. Tudo isso faz parte da síndrome da mulher boazinha. (FRANKEL, 2006, p. 248; grifos nossos)

Do nosso ponto de vista, essa imagem da mulher como uma pessoa boazinha e acolhedora e pouco adulta e inteligente tem um papel muito importante no discurso de autoajuda para mulheres, isto é, funciona como uma de suas principais condições de produção. Afinal, como se trata de um discurso que se destina a passar um ensinamento específico às mulheres (como se comportarem a fim de se tornarem "mulheres inteligentes e capazes"), é um discurso que só tem validade se as mulheres realmente necessitarem desse tipo de conhecimento, caso em que as mulheres corresponderiam efetivamente ao que prescrevem os estereótipos tradicionais do gênero.

Assim, o discurso de autoajuda para mulheres sobre finanças considera que o comportamento correto a ser adotado pelas mulheres é ser menos boazinha, ou seja, mais dura, mais egoísta, menos emotiva, o que significa deixar de lado as características que tradicionalmente são associadas às mulheres, conforme podemos notar quando recuperamos o conteúdo dos estereótipos tradicionais de gêneros, segundo os quais os homens são frequentemente estereotipados como competentes, assertivos, independentes e orientados para a realização, enquanto as mulheres não são; as mulheres, por sua vez, são geralmente estereotipadas como calorosas, sociáveis, interdependentes e orientadas para as relações, enquanto os homens não. ${ }^{8}$

Essas diferenças associadas aos estereótipos tradicionais de gênero são explicitamente assumidas no discurso. Muitas vezes, a enunciadora se vale das diferenças entre esses estereótipos com o propósito de fazer com que a enunciatária entenda que há um desequilíbrio entre os comportamentos e condições de homem e de mulher em relação à administração de dinheiro: assim, no discurso que a enunciatária deve exorcizar, estão enunciados que reproduzem claramente essas diferenças, tais como "as mulheres não dão para matemática - e isso inclui dinheiro" ou "os homens são mais expertos que as mulheres em relação a dinheiro" (FRANKEL, 2006, p. 36-37).

Em dado momento da obra, a enunciadora propõe à enunciatária fazer uma autoavaliação sobre as razões de não estar enriquecendo por meio de uma lista

\footnotetext{
${ }^{8}$ Cf. Fiske et al. (2007).
} 
dicotômica de comportamentos de homens e de mulheres, chamando de pontos fracos aqueles relacionados à mulher. Dentre esses comportamentos estão listados como tipicamente masculinos a assunção de riscos ao fazer investimentos e o conhecimento sobre como investir bem, enquanto as mulheres comportam-se de maneira cautelosa na hora de investir e esperam que os outros saibam mais que elas. Além disso, os homens gravitam em torno de empregos bem pagos enquanto as mulheres exercem profissões assistenciais.

Nesses termos, o discurso de autoajuda para mulheres sobre finanças propõe que a enunciatária adote comportamentos que considera como sendo tipicamente masculinos, numa atitude claramente sexista, conforme ilustram os excertos abaixo:

(28) Se você não está acumulando a quantidade de dinheiro de que precisa para ser independente financeiramente, pergunte-se por que. Você se sai melhor desempenhando o papel de "mulher boazinha" do que participando do jogo financeiro? Não é necessário ter uma dosagem muito alta de testosterona para ser competitiva (...). Um motivo pelo qual os homens têm mais probabilidade que as mulheres de serem ricos é que eles sabem o que significa entrar no jogo para vencer (FRANKEL, 2006, p. 52).

(29) Quando os homens não querem uma coisa, dão-lhes as costas, fecham a porta ou desligam o telefone. Já nós, mulheres, não queremos ferir os sentimentos de ninguém, não queremos parecer mal-educadas ou, pior ainda, não queremos que ninguém pense mal de nós. É por isso que damos dinheiro a pessoas que nos fazem sentir culpa por não comprar seus produtos e serviços (FRANKEL, 2006, p. 264).

Como observamos nos excertos, a enunciadora enaltece certas características consideradas como masculinas. Assim, ainda que a intenção da enunciadora seja, à primeira vista, positiva, do ponto de vista das lutas feministas, isto é, quer auxiliar as mulheres a obterem sucesso no mundo das finanças, um discurso como esse produz efeitos para além de seus objetivos assumidos, ao pressupor que os estereótipos tradicionais de gêneros são verdadeiros, colaborando, desse modo, para reforçar a sua circulação e para fixar seus conteúdos. Observemos outro excerto de mesma natureza:

(30) Como todos sabemos, o ego masculino é uma coisa frágil. Andamos sobre ovos quando surge uma questão espinhosa, evitamos perguntas necessárias e aceitamos decisões, tudo em nome da preservação do ego de um homem. Nós nos vemos tomar caminhos que talvez não sejam de nosso interesse e malbaratar nosso dinheiro, ganho com tanta dificuldade. A culpa é deles? Claro que não! Somos nós que estamos fazendo o jogo da "boa menina" e cuidando mais deles que de nós mesmas. (FRANKEL, 2006, p. 81). 
Ainda que, a princípio, seja possível identificar em (30) uma mensagem positiva, ela está repleta de pressuposições que afetam negativamente as mulheres. A enunciadora afirma que a personalidade do homem é complicada, que eles têm ego inflamado. Logo em seguida, não só julga a atitude da mulher, mas também atribui às próprias mulheres a culpa pelo fato de os homens serem como são - o que não deixa de expressar uma ideologia machista.

Notamos ainda, que, também de um ponto de vista sexista, o discurso de autoajuda reproduz outro estereótipo associado às mulheres, isto é, a imagem da mulher competente, bem-sucedida, porém fria, isto é, "não boazinha", nos termos do discurso em análise. Notamos essa imagem de mulher "fria, mas competente" em excertos como os apresentados a seguir:

(31) Dê a si mesma permissão para ser egoísta. Ao menos é isso o que parece quando você investe tempo em si mesma - egoísta. (FRANKEL, 2006, p. 71)

(32) Quando discutir questões econômicas, concentre-se exclusivamente nos fatos, não nas personalidades. Se o outro quiser levar as coisas para o lado pessoal, adquira o hábito de dizer "não se trata de você. Trata-se de bens e de encontrar formas de multiplicá-los". (FRANKEL, 2006, p. 82)

Desse ponto de vista, pode-se dizer que o discurso de autoajuda hostiliza, de certa forma, as mulheres profissionais bem-sucedidas ao caracterizá-las como mulheres mais frias, ou melhor, ao associá-las a esse estereótipo da mulher de sucesso fria. Esse tipo de preconceito é comum contra as mulheres que, no mercado de trabalho da administração de negócios e gestão de dinheiro, podem ameaçar a dominância masculina: como bem observam Fiske et al. (2007), as mulheres que podem ameaçar os homens são comumente estereotipadas como perigosamente capazes, mas frias e nada amigáveis.

\section{CONSIDERAÇÕES FINAIS}

Neste trabalho, analisamos a expressão lexical da modalidade em uma obra de autoajuda sobre finanças para mulheres, com o objetivo de traçar o perfil da enunciadora do discurso. A análise revela a existência de vários tons: conviç̧ão, ligado à expressão da modalidade epistêmica; otimismo, ligado à expressão da modalidade facultativa; esperança, ligado à expressão da modalidade volitiva. Entre esses tons, predomina um tom de autoridade, ligado à expressão da modalidade deôntica, mas também reforçado pelas ocorrências de verbos no modo imperativo e pelos valores deônticos assumidos pela modalidade volitiva em determinados contextos.

Com relação à alta frequência da modalidade epistêmica e os contextos em que serviu à expressão da dúvida, que a princípio poderiam ser tomados como indícios de incerteza e de insegurança por parte da enunciadora, a análise revela que não se trata, na verdade, de uma autêntica manifestação de dúvida, nem de um 
tom de incerteza. O que verificamos, nesses casos, é uma estratégia discursiva que conduz a uma aproximação entre enunciadora e enunciatária quando a primeira se mostra menos convicta e, portanto, menos autoritária.

$\mathrm{O}$ tom de autoridade que predomina na obra diz respeito à imagem de uma enunciadora assertiva, direta e convicta ("a mulher adulta"), que funciona como um contraponto à imagem de mulher que a obra critica, isto é, a de mulher boazinha (insegura, com medo de investir, que não sabe lidar com o próprio dinheiro, cooperativa e que não pensa em si própria), e que reproduz o conteúdo do estereótipo tradicional de gênero feminino.

Por fim, a análise que desenvolvemos sobre as imagens de mulher no discurso de autoajuda evidencia a heterogeneidade constitutiva desse discurso: ao verificarmos a presença não só do discurso feminista como também do discurso machista, revelamos o caráter contraditório de um discurso que, supostamente, está inteiramente a serviço dos interesses das mulheres, mas infelizmente não escapa de reforçar velhos valores machistas.

\section{REFERENCIAS}

ALVES, J. E. D. Desafios da equidade de gênero no século XXI. Estudos Feministas, Florianópolis, v. 24, n. 2, p. 629-638, 2016.

BIROLI, F. Gênero e desigualdades: limites da democracia no Brasil. São Paulo: Boitempo, 2018.

BRUNELLI, A. F. O sucesso está em suas mãos: análise do discurso de autoajuda. 2004. 149f. Tese (Doutorado em Linguística) - Instituto de Estudos da Linguagem, Universidade Estadual de Campinas, Campinas.

BRUNELLI, A. F.; GASPARINI-BASTOS, S. D. Os valores do verbo modal poder em português: da língua ao discurso. In: XV Congreso Internacional de ALFAL, 2008, Montevideo-Uruguai. Actas. Montevideo-Uruguai: ALFAL, 2008.

BRUNELLI, A. F.; GASPARINI-BASTOS, S. D. O comportamento do verbo modal poder no discurso de autoajuda: uma investigação no português e no espanhol. Estudos Linguísticos, v. 40, n. 1, p. $61-70,2011$.

BRUSCHINI, C. O trabalho da mulher brasileira nas décadas recentes. Estudos Feministas, Rio de janeiro, ano 2, p. 179-199, 1994.

CASIMIRO, S. Um estudo das modalidades deôntica e volitiva nos discursos do presidente Lula. 2007. 108f. Dissertação (Mestrado em Estudos Linguísticos) - Instituto de Biociências, Letras e Ciências Exatas, Universidade Estadual Paulista, São José do Rio Preto.

DAMIANI, D.; ALMEIDA, C. Ganhar, gastar, investir: o livro do dinheiro para mulheres. Rio de Janeiro: Sextante, 2016.

FISKE, S. T.; CUDDY, A. J. C.; GLICK, P. Universal dimensions of social perception: warmth and competence. Trends in Cognitive Science, v. 11, n. 2, p. 77-83, 2007. 
FRANKEL, L. P. Mulheres ousadas chegam mais longe. São Paulo: Editora Gente, 2005.

FRANKEL, L. P. Mulheres boazinhas não enriquecem. São Paulo: Editora Gente, 2006.

FURLAN, M. M. Cenas de enunciação e ethos discursivo: análise do discurso de autoajuda para adolescentes. 2013. 108f. Dissertação (Mestrado em Estudos Linguísticos) - Instituto de Biociências, Letras e Ciências Exatas, Universidade Estadual Paulista, São José do Rio Preto.

GASPARINI-BASTOS, S. D. Os constituintes extrafrasais com valor epistêmico: análise de entrevistas jornalísticas do espanhol e do português. 2004. 161f. Tese (Doutorado em Linguística e Língua Portuguesa) - Faculdade de Ciências e Letras, Universidade Estadual Paulista, Araraquara.

HENGEVELD, K. Illocution, mood, and modality. In: BOOIJ, G.; LEHMANN, C.; MUGDAN, J. (eds.) Morphology: a handbook on inflection and word formation. v. 2. Berlin: Mouton de Gruyter, 2004. p. 1190-1201.

HENGEVELD, K. The grammaticalization of tense and aspect. In: HEINE, B.; NARROG, H. (eds.). The Oxford handbook of grammaticalization. Oxford: Oxford University Press, 2011. p. 580594.

HENGEVELD, K.; HATTNHER, M. M D. A. Four types of evidentiality in the native languages of Brazil. Linguistics, v. 53, n. 3, p. 479-524, 2015.

MAINGUENEAU, D. Ethos, cenografia, incorporação. In: AMOSSY, R. (org.). Imagens de si no discurso: a construção do ethos. São Paulo: Contexto, 2005. p. 69-92.

MAINGUENEAU, D. A propósito do ethos. In: MOTTA, A. R.; SALGADO, L. (orgs.). Ethos discursivo. São Paulo: Contexto, 2008. p. 11-29.

MAINGUENEAU, D. Doze conceitos em análise do discurso. POSSENTI, S.; SOUZA E SILVA, M. C. P. (orgs.). São Paulo: Parábola, 2010.

NEVES, M. H. M. A modalidade. In: KOCH, I. G. V. (org.). Gramática do português falado 6: Desenvolvimentos. Campinas: Editora da UNICAMP/FAPESP, 1996. p. 163-195.

NEVES, M. H. M. Imprimir marcas no enunciado. Ou: a modalização na linguagem. In: NEVES, M. H. M. Texto e gramática. São Paulo: Contexto, 2006. p. 152-221.

OLBERTZ, H.; GASPARINI-BASTOS, S. D. Objective and subjective deontic modal necessity in FDG - evidence from Spanish auxiliary expressions. In: MACKENZIE, J. L.; OLBERTZ, H. (eds.) Casebook in Functional Grammar. Amsterdam: John Benjamins, 2013. p. 277-300.

ORMAN, S. As mulheres e o dinheiro. Rio de Janeiro: Nova Fronteira, 2007.

UEDA, M. B. O ethos das obras de autoajuda para a terceira idade. 2014. 104f. Dissertação (Mestrado em Estudos Linguísticos) - Instituto de Biociências, Letras e Ciências Exatas, Universidade Estadual Paulista, São José do Rio Preto.

Recebido: 25/03/2019

Aceito: 29/05/2019

Publicado: 11/06/2019 